\title{
Educação infantil e intervenção motora: um olhar a partir da teoria bioecológica de Bronfenbrenner
}

\author{
Bárbara Coiro Spessato* \\ Nádia Cristina Valentini** \\ Ruy Jornada Krebs***
}

Adriana Berleze $e^{* * * *}$

\begin{abstract}
Resumo: Este estudo investigou a relação entre o enriquecimento do contexto da creche e a legislação vigente. Três estudos de caso com bebês foram conduzidos no paradigma da Teoria Bioecológica. Os resultados demonstraram que os bebês apresentaram novas competências de manipulação, controle postural e interação social. Entretanto a qualidade dos cuidados oferecidos na creche era restrita à higiene e alimentação. A intervenção pode ser implementada no espaço da creche; entretanto faz-se necessário se fazer cumprir a legislação no que diz respeito à formação e capacitação de educadores e à razão criança-educadores para efetivamente transformar o caráter assistencialista da educação infantil.

Palavras-chave: Creches. Legislação como assunto. Intervenção precoce (Educação). Educação infantil.
\end{abstract}

\section{INTRODUÇÃO}

Esta pesquisa é fruto de uma crescente preocupação com relação à educação infantil no que diz respeito ao caráter educacional e ao desenvolvimento de bebês que frequentam creches no primeiro ano de vida. Vários fatores ambientais influenciam o desenvolvimento

\footnotetext{
* Mestre em Ciências do Movimento Humano. Professora da Escola de Educação Física da UFRGS. Programa de Pós-graduação em Ciências do Movimento Humano. Porto Alegre, RS, Brasil. E-mail: barbaraspessato@gmail.com

"* PhD. Health And Human Performance. Professor Adjunto da Escola de Educação Física da UFRGS. Departamento de Educação Física. Porto Alegre, RS, Brasil. E-mail: nadiacv@esef.ufrgs.br ${ }^{* * *}$ PhD. Educação Física. Professor da Universidade Estadual de Santa Catarina. Florianópolis, SC, Brasil. E-mail: d2rjk@pobox.udesc.br

**** Doutora em Ciências do Movimento Humano. Professora da Universidade da Região da Campanha. Departamento de Educação Fisica. São Gabriel, RS, Brasil. E-mail: adrianaberleze@yahoo.com.br
} 
infantil, como, por exemplo, uma nutrição adequada, condições sociais favoráveis (água potável, saneamento adequado) e educação com qualidade. Os investimentos na criança são mais eficientes e garantem retornos maiores do que qualquer outro investimento por parte do governo, pois esse investimento contribui para a igualdade social e ascensão econômica (SANTOS, 2004). Entretanto, esses fatores ainda não recebem da sociedade em geral a preocupação devida, pois uma menor preocupação com o caráter educacional necessário para o desenvolvimento de bebês se observa nos contextos das creches e dos berçários (ALMEIDA, VALENTINI, LEMOS, 2005; ARNS, 1998; HUIJBREGTS, LESEMAN, TAVECCHIO, 2008).

Diversos estudos demonstram os prejuízos acarretados pelo atraso no desenvolvimento na primeira infância, prejuízos esses que acabam se tornando preocupações sociais (ALMEIDA, 2004; ALMEIDA, VALENTINI, GUERREIRO, 2005; BOMBARDA, 2008; RAMEY, RAMEY, 1998; RAMEY, BRYANT, SUAREZ, 1990; RECH, 2005; WASIK, RAMEY, BRYANT, 1990). Atrasos na primeira infância estão relacionados com posterior evasão escolar, gravidez na adolescência e delinquência juvenil (RAMEY, BRYANT, SUAREZ, 1990). Considerando-se que o desenvolvimento motor depende da interação entre o indivíduo, o ambiente e a tarefa(KREBS, 1995; ROSE, 1997), um ambiente inadequado, inibidor ou pouco estimulante pode repercutir de forma negativa no desenvolvimento infantil (BOATO, 2003; RAMEY, BRYANT, SUAREZ, 1990). Em uma visão dinâmica do desenvolvimento da criança, a preocupação em saber qual a natureza, inata ou adquirida, que determina a maneira como a criança cresce e se desenvolve, passa a ser até mesmo pouco relevante; pois se a hereditariedade determina o potencial humano, ela é o meio que intermedia as conquistas do ser humano (BRONFENBRENNER, 1996; GALLAHUE, OZMUN, 2001; HAYWOOD, GETCHELL, 2004; NEWELL, 1986).

As interações (hereditárias e ambientais) acabam influenciando as principais mudanças da criança, ocasionando o desenvolvimento da mesma em ritmos e intensidades diferentes (BEE, 1996; PAPALIA, OLDS, 2000). Considerando-se que crianças conhecem o mundo a partir da exploração motora, o seu desenvolvimento global dependerá

Movimento, Porto Alegre, v. 15, n. 04, p. 147-173, outubro/dezembro de 2009. 
do sucesso que elas vivenciarem nessa etapa inicial. Intervir no contexto da creche, ou da escola de educação infantil, tornando-o um ambiente estimulante e educacional, pode favorecer o desenvolvimento das crianças. A intervenção nessa faixa etária se propõe a modificar a qualidade de estímulos proporcionados às crianças, alterando o ambiente imediato, ou criando um novo sistema no qual a criança é inserida. Em ambos os casos, diversas novas tarefas são propostas e acrescentadas ao dia-a-dia da criança. À medida que esses estímulos modificam o desenvolvimento global da criança, eles alteram a maneira na qual a criança interage com o ambiente. A mudança na forma de interação pode favorecer a criação de uma maior riqueza de estímulos e curiosidade, que levará a descobertas por parte da criança. Essas descobertas possibilitam ao bebê influenciar o ambiente em que está inserido, gerando possíveis mudanças nos papéis (BEZIER, HUNSINGER, 1994; BROFENBRENNER, 2002; KREBS, 2003). Essa complexa interação dinâmica entre os atributos da pessoa em desenvolvimento e as pressões do contexto em que o desenvolvimento se dá e que ocorrem ao longo do tempo está representada (figura 1) no modelo bioecológico (BRONFENBRENNER, 1995; BRONFENBRENNER, CROUTER, 1983; BRONFENBRENNER, MORRIS, 1998; BRONFENBRENNER, LÜSHER, 1995).

No Brasil, o direcionamento das pesquisas fundamentadas na teoria bioecológica focaliza-se principalmente em estudos descritivos com crianças em idade escolar (KREBS, ZUCHETTO, 2008; VIEIRA, 2003; COPETTI, 2003, BERLEZE, 2002; COPETTI; KREBS, 1997). Alguns estudos brasileiros (e.g. MELCHIORI; ALVES; SOUZA; BUGLIANI, 2007; BHERING, NEZ, 2002) investigam bebês e o seu contexto considerando o microssistema (creche, ambiente familiar). Infelizmente a literatura é carente de estudos que relacionem seus resultados com outros sistemas presentes no modelo bioecológico (e.g. mesossistema, exossistema, macrossistema) e de estudos interventivos com bebês dentro dessa perspectiva teórica. As intervenções com bebês tendem a centrar-se em várias dinâmicas de intervenções, verificando a influência das mesmas no progresso motor (BOMBARDA, 2008; ALMEIDA, 2005; RECH, 2005). Nesta pers-

Movimento, Porto Alegre, v. 15, n. 04, p. 147-173, outubro/dezembro de 2009. 
pectiva, retratar a realidade do contexto sócio-cultural nas quais as crianças estão inseridas; produzindo informações confiáveis, que possam vir a auxiliar na identificação de problemas o mais precocemente possível, reforçam a importância desta pesquisa. A implementação de estratégias a ser incorporadas na organização familiar e na creche pode repercutir em ações efetivas que possam provocar modificações positivas para os bebês.

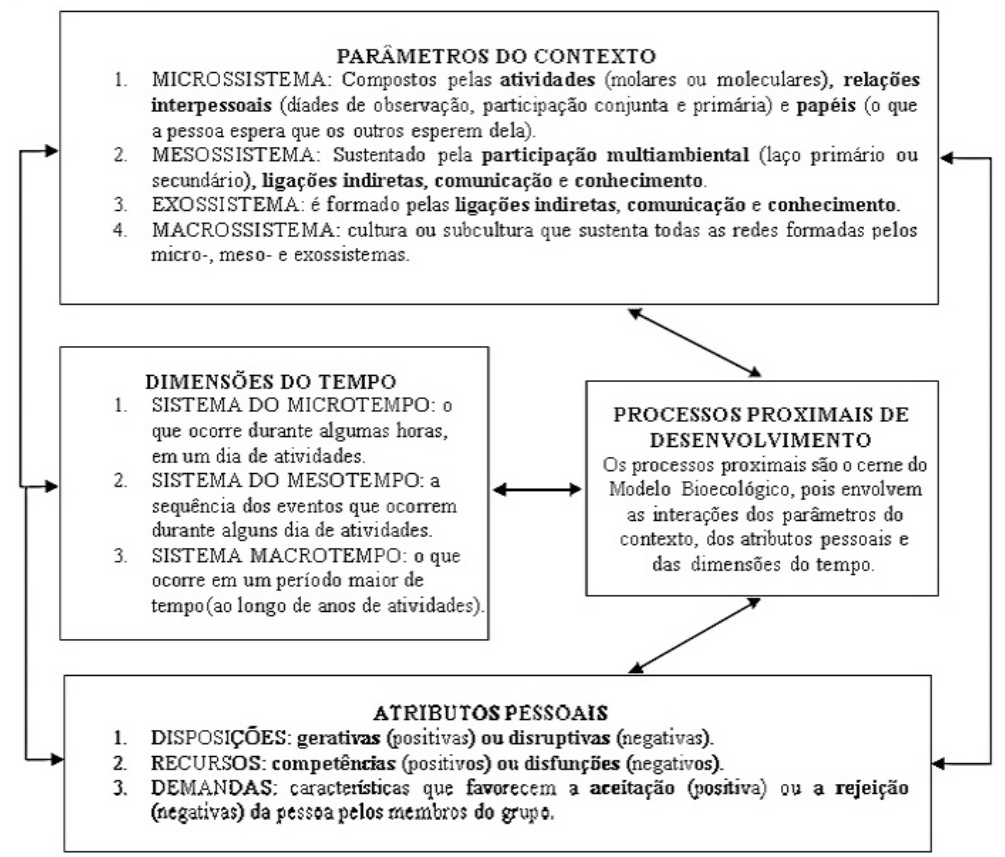

Figura 1. Modelo de interação dos elementos da Teoria Bioecológica de Bronfenbrenner (KREBS; ZUCHETTO, 2008)

Um dos fatores determinantes para o desenvolvimento infantil são as circunstâncias sociais e as possibilidades de escolhas a que a família tem acesso. Dessa forma, este estudo investigou a relação entre o microssistema, a creche que o bebê frequenta, enriquecido por meio de uma intervenção motora, e o macrossistema, o qual envolve a legislação que regulamenta essas creches e as políticas públicas para infantes. Para que esse objetivo fosse alcançado, buscou-se compreender como o potencial educacional do microssistema se relaciona com as diretrizes educacionais estabelecidas pela legislação competente.

Movimento, Porto Alegre, v. 15, n. 04, p. 147-173, outubro/dezembro de 2009. 


\section{MATERIAIS E MÉTOdOS}

Os procedimentos metodológicos deste estudo estão apoiados nos princípios da confirmação e descoberta de delineamentos bioecológicos (BRONFENBRENNER, 2005). Quanto à confirmação, este estudo implementou hipóteses e delineamentos alternativos de pesquisa a fim de verificar a real aplicabilidade e validade dos resultados obtidos e a sua replicabilidade no cotidiano dos bebês. Quanto à descoberta, a parte empírica desta pesquisa apoiou-se em três estudos de caso com bebês que participaram de uma intervenção motora no ambiente da creche no primeiro ano de vida. Com esse delineamento pelo modo da descoberta, busca-se prover bases científicas para o delineamento de políticas sociais e programas mais efetivos, que possam se contrapor às novas e emergentes influências disruptivas ao desenvolvimento humano.

\subsection{DELIMITAÇÃO E INTERPRETAÇÃO DOS PARÂMETROS DO CONTEXTO DO ESTUDO}

O estudo do desenvolvimento infantil interpretado pelos parâmetros do contexto bioecológico engloba: a) a criança em desenvolvimento, em que o crescimento está sempre em constante progresso, reestruturando seu meio; b) a reciprocidade, na qual ocorre uma interação entre a criança e o meio ambiente, ou seja, o meio ambiente exerce influência no desenvolvimento infantil; e c) as interconexões entre esses ambientes e as influências externas provenientes de meios mais amplos. Esses ambientes são chamados de micro-, meso-, exo- e macrossistema. Eles são dispostos na ordem de círculos concêntricos, desde a área mais interna até a mais externa, sendo que todos estão dentro da dimensão de tempo (BRONFENBRENNER, 1996). O microssistema está relacionado ao sistema mais imediato do bebê no qual o mesmo participa ativamente em um ambiente, como a creche, por exemplo. $\mathrm{O}$ mesossistema inclui as inter-relações entre dois ou mais ambientes do microssistema em que o bebê participa ativamente - a família e a creche. Já o exossistema compreende as interligações entre dois ou mais ambientes, sendo que em pelo menos um desses ambientes a criança não está inserida. Porém esse afeta indiretamente seu desen-

Movimento, Porto Alegre, v. 15, n. 04, p. 147-173, outubro/dezembro de 2009. 
volvimento, tendo-se como exemplo o trabalho dos pais. O macrossistema é o último nível do modelo, podendo ser explicado como o contexto social mais abrangente, que acaba influenciando o desenvolvimento da criança. Como exemplo desse nível tem-se o sistema público de saúde e a educação oferecidos no nosso país. Com base nesses elementos, foi delineado o modelo para a análise utilizada no presente estudo. Esse modelo é mostrado na figura 2.

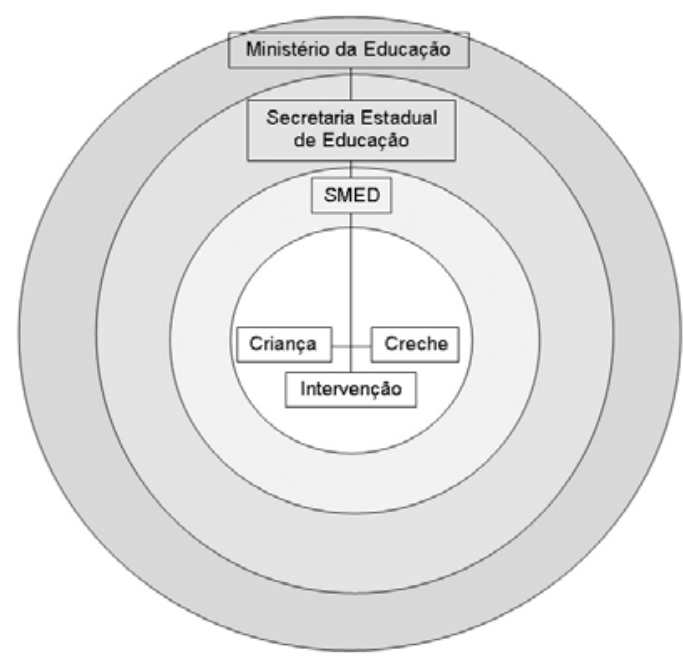

Figura 2. Os contextos da Educação Infantil no presente estudo a partir da Teoria Bioecológica de Bronfenbrenner

No modelo apresentado na figura 2, podemos perceber as interações construídas a partir da intervenção que os bebês dos casos investigados receberam no microssistema creche. Esse microssistema mantém uma rede sistêmica com as políticas públicas regional, estadual e federal, representadas pelas respectivas Secretarias de Educação Municipal e Estadual e Ministério da Educação. A União exerce suas competências relacionadas à educação por meio do Ministério da Educação, sendo elas: formulação da política nacional; coordenação nacional (articulação com outros órgãos e ministérios que tenham políticas e programas para crianças de 0 a 6 anos); estabelecimento de

Movimento, Porto Alegre, v. 15, n. 04, p. 147-173, outubro/dezembro de 2009. 
diretrizes gerais; assistência técnica e financeira aos Estados, ao Distrito Federal e aos Municípios; coleta, análise e disseminação de informações educacionais; regulamentação e normatização pelo CNE (Conselho Nacional de Educação); formação universitária de professores; e fomento à pesquisa. Os Estados exercem suas competências por meio da Secretaria Estadual da Educação, sendo essas: formulação da política estadual; coordenação estadual; execução das ações estaduais; assistência técnica e financeira aos Municípios; normatização pelo CEE (Conselho Estadual de Educação); autorização, reconhecimento, credenciamento, fiscalização, supervisão e avaliação dos estabelecimentos do seu sistema de ensino; formação universitária de professores; fomento à pesquisa; formação de professores na modalidade Normal, em nível médio. Já o Município exerce suas competências por meio da Secretaria Municipal de Educação, sendo elas: formulação da política municipal; coordenação da política municipal; execução dos programas e das ações; normatização pelo CME (quando houver Conselho Municipal de Educação); autorização, reconhecimento, credenciamento, fiscalização, supervisão e avaliação dos estabelecimentos do seu sistema de ensino; formação continuada de professores em exercício; fomento à pesquisa.

\subsection{A SELEÇÃo dos CASOS PARA O ESTUdo}

A seleção dos casos para o estudo aconteceu de maneira não probabilística, intencional, na população de crianças de creches conveniadas com a rede pública e de caráter filantrópico de Porto Alegre, RS, que autorizaram a utilização das suas dependências, via termo de autorização institucional. Quarenta bebês com idades de seis a oito meses de vida participaram de um estudo prévio de intervenção motora (ALMEIDA, 2004). Desses 40 bebês, três permaneceram com atrasos motores após o primeiro estudo, evidenciando a necessidade de continuidade da intervenção. Para assegurar o anonimato, os bebês participantes tiveram seus nomes reais substituídos por nomes fictícios. O termo de consentimento livre e informado foi obtido para cada participante, e a pesquisa foi aprovada pelo comitê de ética da UFRGS (Processo $n^{\circ}$ 2003109).

Movimento, Porto Alegre, v. 15, n. 04, p. 147-173, outubro/dezembro de 2009. 


\section{Artigos Orifinais Bárbara Coiro Spessato, et al.}

\subsection{PROCEDIMENTOS PARA COLETA DOS DADOS E INSTRUMENTOS UTILIZADOS}

Os três bebês selecionados para este estudo foram avaliados antes e após o período da intervenção por meio da Escala de Desenvolvimento do Comportamento da Criança no Primeiro Ano de Vida (PINTO; VILANOVA; VIEIRA, 1997). A fim de garantir a objetividade das avaliações esta foi realizada por três avaliadores - sendo dois independentes do pesquisador - que apresentaram 100\% de concordância entre eles. Os comportamentos avaliados por meio da Escala de Desenvolvimento do Comportamento da Criança no Primeiro Ano de Vida(PINTO; VILANOVA; VIEIRA, 1997) foram: a) axial espontâneo não comunicativo - postura e deslocamento, arrastar, engatinhar, caminhar; b) axial espontâneo comunicativo - comunicação verbal, emissão de sons guturais, vocálicos e se o bebê repete a mesma sílaba; c) axial estimulado não-comunicativo - se o bebê procura localizar o som e apresenta esquiva frente a estranhos; d) axial estimulado comunicativo - resposta motora a estímulo verbal ou corporal, que indica se o bebê brinca de "esconde-achou" e reage a jogos corporais; e) apendicular espontâneo não-comunicativo - manipulação de objetos, se o bebê leva a mão à boca, tem preensão palmar simples, pinça; f) apendicular espontâneo comunicativo - manipulação em relação ao outro, se o bebê toca nos óculos, rosto e cabelos de adultos; g) apendicular estimulado não-comunicativo - manipulação dos objetos apresentados, se o bebê tenta pegar um objeto suspenso, balança um brinquedo sonoro, chocalha; h) apendicular estimulado comunicativo - resposta a solicitações verbais, dá "tchau", atende a solicitações simples, faz carinho. Esses oito itens foram avaliados em uma escala tipo "Likert", com cinco níveis: 1) atraso, 2) de risco, 3) regular, 4) bom, 5) excelente. $\mathrm{Na}$ avaliação, foram utilizados brinquedos (chocalhos, caminhão de pinos, espelho, entre outros) a fim de investigar a presença das diferentes habilidades motoras por meio de atividades lúdicas.

\subsection{IMPLEMENTAÇÃO DO PROGRAMA DE INTERVENÇÃO}

O programa de intervenção foi realizado três vezes por semana, durante dois meses, em um total de 18 intervenções devido às ausências dos bebês. Durante todas as etapas do estudo, os bebês foram fil- 
mados. Todas as observações realizadas durante a intervenção e por meio das filmagens foram registradas em um diário de campo que serviu como suporte para análise e discussão dos resultados. O diário descreve as observações feitas durante a intervenção relativa à motricidade, interação, ao comportamento dos bebês e funcionamento da creche. A base das descrições do diário de campo referentes ao desenvolvimento motor foi baseada na Alberta Infant Motor Scale (PIPER; DARRAH, 1994).

As intervenções eram realizadas três vezes por semana, na própria creche, com a sessão dividida em três partes: a) perseguição visual, b) exploração sensório-motora e c) deslocamento. A perseguição visual era realizada com coloridos chocalhos, bichinhos de pelúcia ou borracha e consistia basicamente em mostrar o brinquedo e movimentá-lo, a fim de gerar interesse (disposição gerativa) no bebê, que poderia acompanhar o movimento com o olhar e tentar alcançálo (competência ou disfunção). Caso o bebê alcançasse e pegasse o brinquedo, esse era entregue em suas mãos e assim iniciava-se um movimento com outro brinquedo, tirando a atenção do brinquedo inicial e possibilitando a manutenção da dinâmica no período proposto. A exploração sensório-motora consistia basicamente na manipulação de objetos, sendo realizada da seguinte forma: foram apresentados ao bebê brinquedos de diferentes formatos, cores e texturas; caso o bebê perdesse interesse no primeiro brinquedo ou tivesse explorado satisfatoriamente as possibilidades de pegadas, um novo brinquedo era oferecido. Para a realização do deslocamento, o bebê era posicionado em prono e estimulado com brinquedos na linha de visão, sendo então utilizados outros brinquedos sonoros fora da linha de visão para criar a necessidade de troca de postura. $\mathrm{O}$ bebê era deixado livre para resolver quaisquer dificuldades locomotoras (de controle postural e manipulação) que aparecessem durante a intervenção. Quando a resolução do problema motor não era alcançada de forma independente, o bebê recebia auxílio na sua execução. Se, mesmo assim, ele não conseguisse alcançar seu objetivo e apresentasse características de frustração, o problema era solucionado temporariamente, sendo apresentado novamente no decorrer da sessão de forma diferenciada.

Movimento, Porto Alegre, v. 15, n. 04, p. 147-173, outubro/dezembro de 2009. 


\section{Artigos Originais Bárbara Coiro Spessato, et al.}

\section{ANÁLISE dos RESULtAdos}

Os dados foram analisados de forma descritiva e individual, visto que não era objetivo do estudo comparar os bebês entre si, mas sim interpretar os efeitos da intervenção no processo do desenvolvimento do comportamento dos bebês e descrever o contexto da creche. A análise foi realizada a partir da triangulação das informações coletadas na pesquisa de campo, em que se procurou associar à legislação vigente ao referencial teórico, suporte desta pesquisa, aos dados presentes no diário de campo, oriundos da intervenção e da filmagem.

\subsection{Resultados}

\subsubsection{CARACTERIZAÇÃo do AMBIENTE E A ROTINA DIÁRIA DA CRECHE OBSERVADA AO LONGO DA INTERVENÇÃO}

As intervenções foram realizadas em duas creches de Porto Alegre. Essas creches recebem crianças provenientes de lares de baixa renda familiar. A primeira tinha uma média de 11 bebês por atendente, que permaneciam por, no mínimo, 7 horas/dia na creche. Era organizada por um grande número de voluntárias. As educadoras possuíam formação em nível fundamental. Os brinquedos eram escassos, frutos de doações e de movimentos de arrecadação de recursos realizados principalmente pelo voluntariado. A segunda creche assistia em torno de 8 bebês por atendente e apresentava uma maior estrutura no sentido de brinquedos que favoreciam o desenvolvimento dos bebês em comparação com a primeira, mas ainda assim pouco adequados em número e função. As educadoras haviam concluído o ensino médio e não possuíam habilitação em curso superior.

Nas duas creches, os bebês permaneciam a maior parte do dia no berço, o que limitava ainda mais as suas possibilidades de descobertas, além das limitações impostas pelo ambiente físico, restrito a uma única sala. A rotina das creches era estabelecida de acordo com os horários de alimentação e troca de fraldas. Ao chegarem na creche, os bebês recebiam a primeira refeição e logo em seguida começava a primeira sessão de trocas de fraldas. Quando a atendente acabava a troca, tinha

Movimento, Porto Alegre, v. 15, n. 04, p. 147-173, outubro/dezembro de 2009. 
um pequeno intervalo e logo se dava início aos preparativos para a nova refeição, seguida por nova troca de fraldas, de modo que a atendente não tinha muito tempo para brincar e interagir com os bebês.

\subsubsection{CARACTERIZAÇÃO do DESENVOLVIMENTO DOS BEBÊS AO LONGO DA INTERVENÇÃO}

Os atributos pessoais diagnosticados no pré-teste, bem como as competências e as disfunções motoras serão apresentados detalhadamente nos quadros 1 e 2 respectivamente.

\begin{tabular}{|c|c|c|}
\hline & Competências & Descrição do Comportamento \\
\hline \multirow{6}{*}{ João } & $\begin{array}{l}\text { 1- Comportamento axial espontâneo } \\
\text { comunicativo }\end{array}$ & (a) repete os próprios sons, (b) tem reação de esquiva \\
\hline & $\begin{array}{l}\text { 2- Comportamento axial estimulado } \\
\text { não-comunicativo }\end{array}$ & (a) tira pano do rosto, (b) localiza som, (c) segue objeto $180^{\circ}$ \\
\hline & $\begin{array}{l}\text { 3- Comportamento axial estimulado } \\
\text { comunicativo }\end{array}$ & (a) vira-se quando chamado pelo nome \\
\hline & $\begin{array}{l}\text { 4- Comportamento apendicular } \\
\text { espontâneo comunicativo }\end{array}$ & (a) bate nos óculos, no nariz e nos cabelos dos adultos \\
\hline & $\begin{array}{l}\text { 5- Comportamento apendicular } \\
\text { estimulado não-comunicativo }\end{array}$ & (a) tenta pegar objeto suspenso, (b) chocalha \\
\hline & $\begin{array}{l}\text { 6- Comportamento apendicular } \\
\text { estimulado comunicativo }\end{array}$ & $\begin{array}{l}\text { (a) responde "vem", estendendo os braços, (b) bate palmas, } \\
\text { (c) dá "tchau" }\end{array}$ \\
\hline \multirow{6}{*}{ Ana } & $\begin{array}{l}\text { 1- Comportamento axial estimulado } \\
\text { não-comunicativo }\end{array}$ & (a) sorri e vocaliza diante do espelho, (b) tira pano do rosto \\
\hline & $\begin{array}{l}\text { 2- Comportamento axial estimulado } \\
\text { comunicativo }\end{array}$ & $\begin{array}{l}\text { (a) vira-se quando chamada pelo nome, (b) brinca de esconde-achou, } \\
\text { (c) reage a jogos corporais }\end{array}$ \\
\hline & $\begin{array}{l}\text { 3- Comportamento apendicular } \\
\text { espontâneo não-comunicativo }\end{array}$ & $\begin{array}{l}\text { (a) em prono, alcança objeto, (b) pega objeto após deixá-lo cair, } \\
\text { (c) encontra objeto escondido, (d) usa objeto intermediário }\end{array}$ \\
\hline & $\begin{array}{l}\text { 4- Comportamento apendicular } \\
\text { espontâneo comunicativo }\end{array}$ & (a) bate nos óculos, no nariz e nos cabelos dos adultos \\
\hline & $\begin{array}{l}\text { 5- Comportamento apendicular } \\
\text { estimulado não-comunicativo }\end{array}$ & $\begin{array}{l}\text { (a) tira pinos grandes, (b) tira pinos pequenos, (c) coloca objeto em } \\
\text { recipiente }\end{array}$ \\
\hline & $\begin{array}{l}\text { 6- Comportamento apendicular } \\
\text { espontâneo comunicativo }\end{array}$ & $\begin{array}{l}\text { (a) responde a "vem" estendendo os braços, (b) bate palmas, (c) } \\
\text { executa gestos simples a pedido }\end{array}$ \\
\hline \multirow{5}{*}{ Maria } & $\begin{array}{l}\text { 1- Comportamento axial espontâneo } \\
\text { comunicativo }\end{array}$ & (a) sorri, (b) repete os próprios sons \\
\hline & $\begin{array}{l}\text { 2- Comportamento axial estimulado } \\
\text { comunicativo }\end{array}$ & (a) vira-se quando chamada pelo nome \\
\hline & $\begin{array}{l}\text { 3- Comportamento apendicular } \\
\text { estimulado }\end{array}$ & (a) bate nos óculos, no nariz e nos cabelos dos adultos \\
\hline & $\begin{array}{l}\text { 4- Comportamento axial estimulado } \\
\text { não-comunicativo }\end{array}$ & (a) não sorri e vocaliza diante do espelho \\
\hline & $\begin{array}{l}\text { 5- Comportamento apendicular } \\
\text { estimulado não-comunicativo }\end{array}$ & (a) balança brinquedo sonoro, (b) chocalha \\
\hline
\end{tabular}

Quadro 1. Atributos pessoais diagnosticados no pré-teste como Competências

Movimento, Porto Alegre, v. 15, n. 04, p. 147-173, outubro/dezembro de 2009. 


\section{Antigos Orifinais}

Bárbara Coiro Spessato, et al.

\begin{tabular}{|l|l|l|}
\hline \multicolumn{1}{|c|}{ Disfunção } & \multicolumn{1}{c|}{ Descrição do comportamento } \\
\hline \multirow{5}{*}{ João } & $\begin{array}{l}\text { 1- Comportamento apendicular } \\
\text { espontâneo não-comunicativo }\end{array}$ & $\begin{array}{l}\text { (a) não alcançava objetos em prono, (b) não apanhava objetos após sua } \\
\text { queda, (c) não transferia objetos de uma mão para outra, (d) não segurava } \\
\text { dois pinos em uma mão }\end{array}$ \\
\cline { 2 - 3 } & $\begin{array}{l}\text { 2- Comportamento axial espontâneo } \\
\text { não-comunicativo }\end{array}$ & (a) não engatinhava, (b) não passava da postura prono para sentada \\
\cline { 2 - 3 } Ana & $\begin{array}{l}\text { 3- Comportamento axial estimulado } \\
\text { não-comunicativo }\end{array}$ & $\begin{array}{l}\text { (a) não repetia a mesma sílaba, (b) não combinava as palavras em jogo } \\
\text { silábico }\end{array}$ \\
\hline \multirow{5}{*}{ Maria } & $\begin{array}{l}\text { 1- Comportamento axial espontâneo } \\
\text { não-comunicativo }\end{array}$ & $\begin{array}{l}\text { (a) não engatinhava, (b) não se mantinha em pé com mínimo apoio, } \\
\text { (c) não passava da postura prono para sentada, (d) não caminhava com } \\
\text { auxílio }\end{array}$ \\
\hline & $\begin{array}{l}\text { comunicativo } \\
\text { 1- Comporto axial espontâneo } \\
\text { não-comunicativo }\end{array}$ & $\begin{array}{l}\text { (a) não emitia sons vocálicos, (b) não repetia a mesma sílaba, } \\
\text { (c) não possuía reação de esquiva frente a estranhos }\end{array}$ \\
\cline { 2 - 3 } & $\begin{array}{l}\text { 2- Comportamento apendicular } \\
\text { espontâneo não-comunicativo }\end{array}$ & $\begin{array}{l}\text { (a) não se arrastava, (b) não ficava sentada sem o apoio das mãos, } \\
\text { (c) não se puxava para sentar, (d) não rolava, (e) não se mantinha em pé } \\
\text { com mínimo apoio }\end{array}$ \\
\hline $\begin{array}{l}\text { (a) não alcançava objeto em prono, (b) não usava objeto intermediário, } \\
\text { (c) não retinha dois pinos em uma mão, (d) não tirava pinos pequenos, } \\
\text { (e) não colocava objetos em recipientes }\end{array}$ \\
\hline
\end{tabular}

Quadro 2. Atributos pessoais diagnosticados no pré-teste como Disfunções

\begin{tabular}{|c|c|c|c|}
\hline & Primeiro mês & Segundo mês & Término da intervenção \\
\hline João & $\begin{array}{l}\text { Tinha oito meses, era um bebê bem- } \\
\text { humorado. Quando se sentia } \\
\text { frustrado por não alcançar, desistia } \\
\text { de tentar e olhava para a } \\
\text { interventora na expectativa de } \\
\text { receber o objeto. A postura prona } \\
\text { adotada limitava a manipulação, } \\
\text { pois o bebê não podia pegar objetos } \\
\text { que o fizessem retirar o apoio do } \\
\text { antebraço. A frequência de } \\
\text { manipulação nessa postura não era } \\
\text { muito expressiva. No sétimo dia de } \\
\text { intervenção, o bebê se arrastava } \\
\text { adotando um padrão de } \\
\text { deslocamento para posterior que } \\
\text { dificultava mudanças de direção. A } \\
\text { postura sentada sem o apoio dos } \\
\text { braços era mantida com segurança, } \\
\text { possibilitando a manipulação e } \\
\text { exploração das possibilidades de } \\
\text { pegada. As quedas de objetos eram } \\
\text { bastante frequentes. }\end{array}$ & $\begin{array}{l}\text { O bebê alcança na postura de prono } \\
\text { com o apoio do braço em extensão. } \\
\text { Na postura sentada, o bebê trocava } \\
\text { de posição para prona. Saía da } \\
\text { posição sentada para prona se } \\
\text { empurrando com os braços, não } \\
\text { fazendo uso das pernas. No decorrer } \\
\text { da intervenção, o bebê passou a } \\
\text { engatinhar, fato que também } \\
\text { contribuiu de forma importante na } \\
\text { exploração das possibilidades de } \\
\text { movimento, visto que o bebê tornou- } \\
\text { se capaz de buscar com mais } \\
\text { eficiência o objeto ou evento que } \\
\text { chamava a sua atenção. }\end{array}$ & $\begin{array}{l}\text { O bebê mantinha a postura de gatas } \\
\text { e, sentado, não utilizava o apoio dos } \\
\text { membros superiores. Ele demonstrou } \\
\text { um aumento crescente de interesse } \\
\text { pelas atividades apresentadas, } \\
\text { associadas a uma melhora na } \\
\text { qualidade do movimento. A } \\
\text { manipulação ficou mais precisa tanto } \\
\text { em sedestação como na postura } \\
\text { prono. Ocorreu um aumento na } \\
\text { frequência de quedas na nona e } \\
\text { décima sessão. O controle postural e } \\
\text { o deslocamento melhoraram } \\
\text { sensivelmente, as reações de } \\
\text { equilíbrio tornaram-se mais definidas } \\
\text { e eficientes. Ele se tornou mais ativo } \\
\text { na interação com os objetos e com a } \\
\text { interventora. Ao término da } \\
\text { intervenção o bebê não apresentava } \\
\text { mais atrasos. }\end{array}$ \\
\hline Ana & $\begin{array}{l}\text { Tinha nove meses, apresentava } \\
\text { dificuldades em fixar o olhar nas } \\
\text { pessoas. A interação com a } \\
\text { interventora aconteceu } \\
\text { gradativamente. Arrastava-se com } \\
\text { grande eficiência, fazendo uso dessa } \\
\text { forma de deslocamento raramente } \\
\text { buscando a postura de quatro } \\
\text { apoios. Passou a sorrir mais vezes, a } \\
\text { apontar os brinquedos e a interagir } \\
\text { mais com o ambiente. A } \\
\text { manipulação de objetos foi se } \\
\text { tornando mais precisa e reduzindo o } \\
\text { número de quedas. Adotava a } \\
\text { postura sentada sem apoio dos } \\
\text { braços, mudava de postura com } \\
\text { facilidade. Explorava bastante o } \\
\text { ambiente, mas não da forma } \\
\text { esperada. Dificilmente fixava o } \\
\text { olhar na interventora, educadora ou } \\
\text { mesmo nas outras crianças. } \\
\text { Brincava principalmente sozinha e } \\
\text { fixava o olhar no vazio. }\end{array}$ & $\begin{array}{l}\text { Ficava em quatro apoios } \\
\text { modificados, brincando na posição, } \\
\text { podendo se mover para frente. Essa } \\
\text { postura demonstrava um aumento no } \\
\text { controle postural, pois permitia uma } \\
\text { mudança dinâmica da postura prona } \\
\text { para sentada. Demonstrava interesse } \\
\text { por brinquedos e os manipulava, } \\
\text { porém parecia estar à parte do } \\
\text { ambiente que a cercava. Essa } \\
\text { característica foi sendo minimizada } \\
\text { com o passar do tempo, pois, aos } \\
\text { poucos, o bebê passou a interagir de } \\
\text { forma mais ativa com os outros. }\end{array}$ & $\begin{array}{l}\text { Realizou a caminhada lateral com } \\
\text { apoio, tornou-se eficiente no } \\
\text { deslocamento na posição de gatas. A } \\
\text { perseguiçã̃o visual passou a ser mais } \\
\text { ativa, os brinquedos de borracha e } \\
\text { chocalhos tiveram que ser } \\
\text { substituídos. O bebê não mais } \\
\text { manipulava objetos na postura prona, } \\
\text { passou a se sentar para explorar os } \\
\text { objetos. Adquiriu a habilidade de } \\
\text { deslocar-se de forma eficiente, sendo } \\
\text { necessário modificar a intervenção, } \\
\text { exigindo alterações no tempo de } \\
\text { cada atividade. Mesmo com a } \\
\text { mudança, foi mantido o tempo de } \\
\text { intervenção de } 15 \text { minutos, alterando } \\
\text { somente a distribuição das atividades } \\
\text { de acordo com os interesses do bebê. } \\
\text { O atraso apresentado no início já não } \\
\text { se fazia presente. }\end{array}$ \\
\hline
\end{tabular}

(Continua...)

Movimento, Porto Alegre, v. 15, n. 04, p. 147-173, outubro/dezembro de 2009. 
(continuação)

\begin{tabular}{|c|c|c|c|}
\hline Maria & $\begin{array}{l}\text { Sete meses, interagia e observava o } \\
\text { outro com traços de ansiedade. A } \\
\text { família a vestia, devido à sua } \\
\text { condição socioeconômica, com } \\
\text { roupas menores que seu tamanho, o } \\
\text { que dificultava a sua movimentação. } \\
\text { Não realizava perseguição visual, } \\
\text { fixava o ollhar na interventora. A } \\
\text { manipulação era imprecisa. } \\
\text { Demonstrava descontentamento por } \\
\text { meio do choro na postura prono e } \\
\text { apresentava reações de equilíbrio e } \\
\text { de proteção precárias. O } \\
\text { deslocamento do olhar da } \\
\text { interventora para o objeto aconteceu } \\
\text { progressivamente, sendo } \\
\text { acompanhado por melhoras na } \\
\text { qualidade do movimento, no } \\
\text { aumento da frequência da } \\
\text { manipulação e na maior interação } \\
\text { com o objeto. Em prono as } \\
\text { transferências de peso eram } \\
\text { descontroladas e o movimento } \\
\text { pouco coordenado. Sentada o corpo } \\
\text { começava a buscar a linha média, } \\
\text { mas não permanecia na posição } \\
\text { sozinha. }\end{array}$ & $\begin{array}{l}\text { Passou a manipular na postura prono } \\
\text { adotada. Buscava manter a pegada } \\
\text { inicial, apresentava um número } \\
\text { elevado de quedas do objeto. O bebê } \\
\text { conquistou a postura sentada sem } \\
\text { apoio dos membros superiores. Essa } \\
\text { postura possibilitou uma melhora na } \\
\text { manipulação, visto que o bebê não } \\
\text { mais dependia de auxílio externo } \\
\text { para permanecer sentado. Passou a } \\
\text { brincar com os objetos e reduziu em } \\
\text { parte o tempo de fixação olhando } \\
\text { para a interventora. }\end{array}$ & $\begin{array}{l}\text { Passou a ter maior domínio da } \\
\text { postura prona, sendo capaz de rolar } \\
\text { de prono para supino. Tolerava a } \\
\text { postura prono na penúltima semana } \\
\text { de intervenção desde que o rosto da } \\
\text { interventora estivesse no seu campo } \\
\text { de visão, ou seja, o bebê passou a } \\
\text { tolerar a postura na medida em que } \\
\text { se percebeu mais seguro e } \\
\text { interagindo socialmente. Sentava-se } \\
\text { independentemente e alcançava com } \\
\text { rotação. O alcançar de objetos } \\
\text { suspensos e a manipulação em geral } \\
\text { passaram a ser feitos com maior } \\
\text { precisão. Apesar de a manipulação } \\
\text { de brinquedos apresentar } \\
\text { características rudimentares, foi } \\
\text { possível perceber o progresso nos } \\
\text { movimentos por meio das } \\
\text { características de alcance e pegada } \\
\text { bimanual. Percebeu-se uma redução } \\
\text { no número de quedas dos objetos. } \\
\text { Maria não apresentou atrasos ao } \\
\text { término da intervenção. }\end{array}$ \\
\hline
\end{tabular}

Quadro 3. Comportamentos motores na intervenção

Os bebês apresentaram mudanças positivas ao longo da intervenção nos diferentes comportamentos. Todos os comportamentos respectivos à idade que não eram apresentados no início da intervenção foram sendo conquistados ao longo do período interventivo (quadro 3).

Os bebês apresentaram melhora tanto na manipulação de objetos quanto no controle postural. As conquistas de controle postural e de deslocamento podem ser observadas na figura 3, considerando-se a sessão na qual o comportamento aparece pela primeira vez de acordo com as descrições do diário de campo.

Movimento, Porto Alegre, v. 15, n. 04, p. 147-173, outubro/dezembro de 2009. 


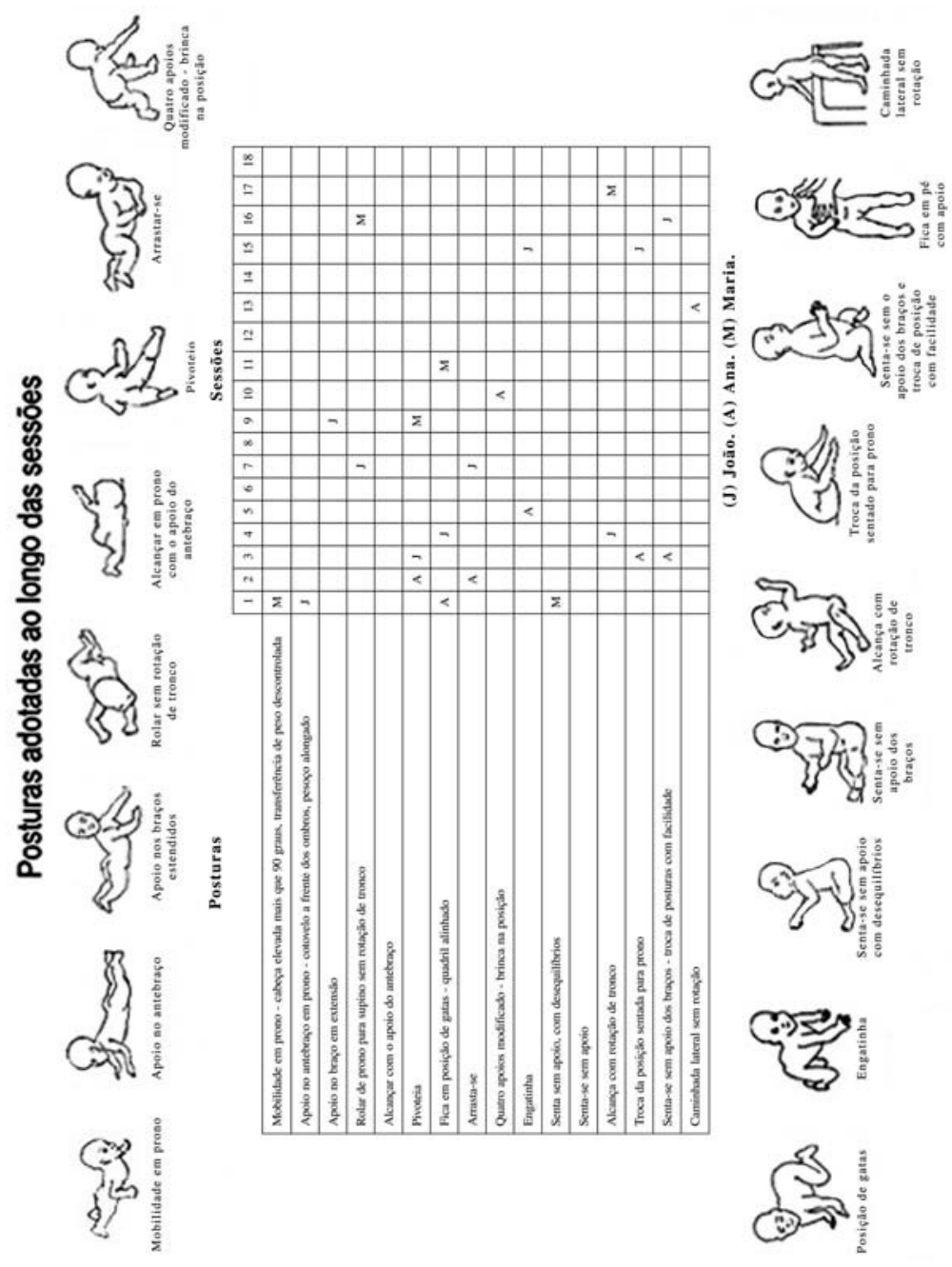

Figura 3. Emergência de comportamentos ao longo das sessões interventivas Fonte: DARRAH, 1994.

Movimento, Porto Alegre, v. 15, n. 04, p. 147-173, outubro/dezembro de 2009. 


\section{DıscussõES}

\subsection{O MICROSSISTEMA E AS MUDANÇAS NAS COMPETÊNCIAS MOTORAS}

Quanto ao contexto, observou-se que a principal função exercida pelas educadoras restringia-se aos cuidados assistenciais, como higiene e saúde dos bebês. Essa função das educadoras de creche vem ao encontro do relatado por Arns (1999) e Almeida, Valentini e Lemos (2005), ou seja, trabalho restrito às tarefas de troca de fraldas e alimentação. Durante a alimentação, momento que poderia ser de interação e trocas entre educadora e bebê, os bebês eram colocados nos carrinhos em círculo, e a educadora entregava uma mamadeira para cada bebê. As crianças mais velhas também ficavam no círculo enquanto a educadora as alimentava individualmente, seguindo a ordem sistematicamente. Nessa situação, a interação também ficava prejudicada, pois apesar da necessidade de ação individualizada, a educadora estava sempre com a atenção voltada para o grupo. O momento de troca de fraldas parecia ser o que proporcionava maior interação entre a díade educadora-bebê. Nessa situação, as educadoras conversavam e mostravam maiores sinais de afetividade. Como os materiais pedagógicos eram escassos, os bebês que não se deslocavam livremente dependiam da interação com a educadora para manipular algum brinquedo. Ao restringir a interação entre educador e criança, o próprio desenvolvimento infantil fica restrito no ambiente institucional (BRONFENBRENNER, 1995; KREBS, 1995). Esse fato foi fortemente observado nas avaliações iniciais, nas quais os bebês participantes evidenciaram atrasos expressivos no desenvolvimento motor, os quais limitavam também suas interações com o ambiente.

Apesar desses atrasos estabelecidos inicialmente, os quais ainda eram prevalentes mesmo após intervenção prévia, a intervenção individualizada e prolongada, realizada no espaço das creches, evidenciou um impacto positivo no comportamento motor. Os resultados do presente estudo são semelhantes aos encontrados por Almeida, Valentini e Lemos (2005) com crianças no terceiro trimestre de vida de creches públicas após 10 sessões interventivas; aos de Rech (2005) com bebês prematuros participando de abordagens interventivas individualizadas e em grupos após 24 sessões; bem como aos de Bombarda (2008),

Movimento, Porto Alegre, v. 15, n. 04, p. 147-173, outubro/dezembro de 2009. 


\section{Astifor Orifimais Bárbara Coiro Spessato, et al.}

também com 24 semanas, com crianças entre 06 e 18 meses de idade que apresentavam atrasos no desenvolvimento motor, vivendo em situação de vulnerabilidade socioeconômica.

A experiência proporcionada pela intervenção auxiliou no aprimoramento de comportamentos presentes no repertório motor do bebê, bem como possibilitou o aumento importante dos estímulos motores, pois bebês que anteriormente recebiam atenção restrita e materiais pedagógicos escassos passaram a experimentar um enriquecimento do ambiente e suas experiências passaram a ser mediadas por um educador (BOATO, 2003; BRONFENBRENNER, 2002; KREBS, 1995; LOBO, GALLOWAY, SAVELSBERGH, 2004). A intervenção possibilitou às crianças uma série de novas interações com a educadora, com um ambiente enriquecido com brinquedos adequados à faixa etária e com as tarefas propostas. As tarefas respeitavam os desejos dos bebês dentro do que a intervenção se propunha. Essa flexibilidade de intervenção permitia uma reciprocidade na interação da interventora e do bebê mesmo que, na maior parte do tempo, as tarefas propostas no protocolo interventivo fossem mantidas.

A complexidade da tarefa interventiva aumentava gradativamente, adequando-se às necessidades desenvolvimentistas dos bebês. Essa mudança no controle da situação parece ser benéfica ao bebê em desenvolvimento (BRONFENBRENNER, 2002; KREBS, 2003), que passa a experimentar o ambiente com maior autonomia. Essa reciprocidade alcançada em uma díade de atividade conjunta (inter-relação entre duas pessoas que realizam algo em conjunto) permitiu o aumento na motivação e no engajamento da intervenção e possivelmente influencia o comportamento da criança mesmo quando um dos participantes, neste caso a educadora, não está presente (BRONFENBRENNER, 2002; KREBS, 2003; LOBO, GALLOWAY, SAVELSBERGH, 2004).

Ainda com relação à interação social, a permanência do maior interesse no educador em vez de no objeto foi observada apenas em um bebê, Maria. Esse interesse geralmente começa a se reduzir dos quatro aos seis meses de idade, sendo a atenção direcionada ao objeto progressivamente (ROCHAT, 2001). Esse atraso acarreta em outras dificuldades, visto que a pegada depende de ações sequenciais como visualização do objeto, perseguição visual, movimento da cabeça em

Movimento, Porto Alegre, v. 15, n. 04, p. 147-173, outubro/dezembro de 2009. 
direção ao objeto e ação do membro superior (LOBO, GALLOWAY, SAVELSBERGH, 2004). Essas dificuldades apresentadas inicialmente por Maria foram sendo superadas gradativamente, ao longo da intervenção.

A estimulação sensório-motora, proposta na intervenção, proporcionou exploração direta das características dos objetos, possibilitando a vivência de uma nova situação interacional. As trocas estabelecidas entre o bebê e a educadora por meio de atividades lúdicas possibilitaram a observação da melhora na habilidade de manipulação e apri-moramento da interação mão-brinquedo nos três bebês (LOBO, GALLOWAY, SAVELSBERGH, 2004). Durante a intervenção, os objetos eram apresentados de diferentes formas na fase da manipulação, pois a forma como o brinquedo é apresentado pode afetar a precisão da pegada (ROCHAT, 2001). As diferentes formas de apresentação do objeto, implementadas nas sessões, geraram a necessidade da descoberta de novas estratégias motoras, possibilitando uma maior exploração das possibilidades de movimentos e, consequentemente, um repertório motor mais amplo. Esse aumento no repertório motor possibilitou aos bebês construírem diferentes percepções do corpo no espaço, que é também um fator importante no ato de alcançar(SPENCER, VEREIJKEN, DIETRICH, THELEN, 2000). A utilização de diferentes estratégias motoras, a exploração das possibilidades de movimento e a observação das consequências dessas ações no ambiente propiciaram aos bebês a utilização de uma seleção dos comportamentos mais bemsucedidos, aprimorando o repertório motor(LOBO, GALLOWAY, SAVELSBERGH, 2004).

O controle postural é uma conquista importante para o aumento das experiências manipulativas, visto que elevar o braço, afastando-o do corpo a fim de alcançar um objeto, causa desequilíbrios que serão compensados por ajustes posturais (SAVELSBERGH, HOFSTEN, JONSSON, 1997). Entretanto, para experienciar esses ajustes os bebês precisam ser manipulados e desequilibrados em suas posturas por meio da intervenção da educadora, situação que não se observava na rotina da creche e foi implementada nas sessões interventivas. Sem esses ajustes, o bebê apresenta maior dificuldade de manipulação e imprecisão no movimento. Bebês que não sentam independentemente

Movimento, Porto Alegre, v. 15, n. 04, p. 147-173, outubro/dezembro de 2009. 


\section{Astifor Orifimais Bárbara Coiro Spessato, et al.}

e recebem estabilização do quadril ainda assim não coordenam a flexão de tronco e o ato de alcançar (SAVELSBERGH, HOFSTEN, JONSSON, 1997). Bebês que sentavam independentemente apresentavam maiores oportunidades de alcance unimanual do que bebês que precisavam de suporte para sentar, evidenciando a forte associação entre o controle postural de sedestação e a coordenação do membro superior no ato de alcançar (ROCHAT, 2001). Para que ocorra um maior número de tentativas de manipulação de objetos é necessário que o bebê tenha estabilidade na postura sentada e seja capaz de corrigir os desequilíbrios causados pela manipulação dos brinquedos. $\mathrm{O}$ enfoque da intervenção proporcionava o mínimo de auxílio possível na manutenção das posturas, exigindo do bebê os ajustes posturais a fim de evitar a queda. Em relação às mudanças nas habilidades de locomoção, as mesmas estão associadas ao aumento da compreensão de profundidade e à noção de posicionamento do próprio corpo no espaço (ROCHAT, 2001). Esse fato parece explicar também, de modo indireto, certa influência do domínio do controle postural na manipulação, visto que o ato de alcançar demanda um cálculo de profundidade a fim de garantir maior precisão do movimento.

\subsection{MACROSSISTEMA INFLUENCIANDO AS PRÁTICAS DOS EDUCADORES}

Considerando-se que o macrossistema determina as políticas que interferirão em todos os demais níveis do modelo bioecológico, os contextos inerentes às creches e instituições de educação infantil devem ser analisados em função de suas interações, também, e das políticas provenientes do macrossistema.

Em 1996, com a Lei de Diretrizes e Bases da Educação Nacional $n^{\circ}$ 9.394, de 20/12/1996, no art. 29, a educação infantil passou a ter maior destaque, sendo considerada parte integrante da educação básica. Ou seja, essa etapa passou obrigatoriamente a ter cunho educacional, e o trabalho realizado nas creches passa a não ser mais assistencialista, tendo, então, a responsabilidade de auxiliar no desenvolvimento das crianças de 0 a 6 anos. Reforçando a importância da educação nessa fase inicial da vida nas disposições gerais da LDBEN, o art. 22, consoante à resolução da CEB n ${ }^{\circ} 1$, de 07/04/1999, art. 3, 
estabelece as finalidades da educação básica, sendo uma delas a de desenvolver o educando, reforçando ainda mais a necessidade de proporcionar experiências que desenvolvam o potencial infantil.

A importância do caráter educacional é demonstrada também no número de crianças frequentando creches; segundo o PNE, em 1998, foram efetuadas 2,7 milhões de matrículas em creches municipais, correspondendo a $66,3 \%$ de todas as matrículas efetuadas. Para garantir que essas crianças vivenciem propostas educativas desde o início da vida, a organização das propostas pedagógicas para educação infantil foi estabelecida com caráter mandatório pelas Diretrizes Curriculares Nacionais de Ensino Infantil (CEB n ${ }^{\circ}$, 7 de abril de 1999). Nesse mesmo sentido, o Referencial Curricular Nacional para a Educação Infantil (RCNEI) propõe bases comuns para a educação nacional, apresentando um conjunto de referências e orientações pedagógicas de facultativa implementação. Pode-se perceber a manutenção dessa estrutura no diagnóstico do Plano Nacional de Educação (Lei ${ }^{\circ}$ 10.172) que apresenta a relação de 21 alunos (de quatro a seis anos de idade) por professor na esfera municipal e de 23,4 alunos na estadual na educação infantil, demonstrando que "a maioria dos ambientes não conta com profissionais qualificados, não desenvolve programa educacional, não dispõe de mobiliário, brinquedos e outros materiais pedagógicos adequados". Quadro semelhante foi encontrado nas creches onde os bebês submetidos à intervenção frequentavam, apresentando um número elevado de bebês por educadores, escassez de material pedagógico, espaço físico restrito e restrição física dos bebês a berços e cadeirinhas, além de possuírem em seus quadros de funcionários, na sua grande maioria, educadores sem qualificação específica para atividades educativas. As educadoras que apresentam falta ou limitação de qualificação específica restringem suas atividades à reprodução de práticas parentais, rotina de cuidados culturalmente construídos. A cultura influencia a forma de interação com os bebês, bem como os próprios valores e crenças das educadoras a respeito do que é importante para o desenvolvimento dos bebês; e, do seu próprio papel na creche (EDWARDS et al., 2005; HARKNESS, et al., 2007; HUIJBREGTS, LESEMAN, TAVECCHIO, 2008). A cultura parece, muitas vezes, exercer um papel de maior importância nas práticas 


\section{Artifor Orifinais Bárbara Coiro Spessato, et al.}

adotadas pelas educadoras do que o conhecimento educacional formal. Embora as mães e educadoras acreditem que o ambiente da creche exerça um papel relevante na educação dos bebês, muitas vezes subestimam a importância das educadoras nesse processo (MELCHIORI, ALVES, SOUZA, BUGLIANI, 2007). Portanto, embora as leis assegurem a necessidade de educação infantil nas creches, muitas vezes a rotina e estrutura de funcionamento das creches - assim como nas creches dos bebês que participaram da intervenção - não favorecem o enfoque educacional, mantendo ainda uma estrutura assistencialista.

Considerando-se a importância da educação na primeira infância a LDBEN, no art. 25, estabelece como objetivo das autoridades responsáveis alcançar uma relação adequada entre o número de alunos e professor, carga horária e as condições materiais do estabelecimento. Essa medida proporciona mais oportunidades para as professoras interagirem com seus alunos nessa fase, uma vez que o tempo não fica restrito a atender às necessidades básicas de todos os alunos. No mesmo sentido a LDBEN no art. 62 estabelece a necessidade de qualificação dos docentes que trabalham com essas faixas etárias, estabelecendo como formação mínima para o exercício do magistério na educação infantil a oferecida em nível médio, na modalidade Normal. O Plano Nacional de Educação aprovado pela Lei $n^{\circ} 10.172$, de 09/01/2001, diagnosticou que na Educação Infantil em torno de $13 \%$ dos professores possuem apenas o ensino fundamental, completo ou incompleto; $66 \%$ são formados em nível médio e somente $20 \%$ têm o curso superior. Foi estabelecido como meta que, em cinco anos da data da aprovação, todos os dirigentes de instituições de educação infantil possuíssem a formação mínima em nível médio na modalidade normal e que em 10 anos tivessem nível superior. A admissão de docentes a partir da vigência do plano deve então respeitar a formação mínima em nível médio na modalidade normal. Essas metas são estabelecidas pela necessidade da formação específica ser necessária para atender às necessidades educacionais de crianças de zero a seis anos.

Entretanto, os resultados do presente estudo sugerem que essas metas até o presente momento não estão sendo alcançadas. Porém cabe enfatizar, que os problemas da efetividade da legislação, enquanto

Movimento, Porto Alegre, v. 15, n. 04, p. 147-173, outubro/dezembro de 2009. 
macrossistema que exerce influência nas experiências motoras nas crianças, não é um único aspecto que afeta diretamente a educação infantil. A cultura comum de um grupo (educadoras de creches), onde se expressa, através de atitudes e ideologias culturais, costumes e valores sociais exercem influências determinantes no desenvolvimento do bebê (BRONFENBRENNER, 1995).

\section{CONSIDERAÇÕES FINAIS}

Considerando o macrossistema, é importante ressaltar que apesar da legislação e suas disposições referentes à Educação Básica, que buscam uma situação ideal de trabalho e educação, percebe-se, através do presente estudo, a dissonância da realidade no microssistema das creches. O presente estudo demonstra, através da análise de três casos, que incorporar práticas educacionais como a intervenção motora nas creches beneficia o desenvolvimento das crianças.

Com relação à intervenção, é importante perceber que o ambiente da creche pode ser estimulante de forma bastante simples. O caráter educacional presente na intervenção pode ser facilmente reproduzido pelas educadoras. As principais dificuldades para que isso ocorra residem no desconhecimento de como tornar educativo para os bebês o tempo passado na creche, o grande número de bebês por educadora responsável e o fato da importância do trabalho realizado pelas educadoras não ser reconhecida. A falta de estímulos e interação das educadoras não era fruto de uma falta de interesse, mas do desconhecimento do potencial educacional dos seus trabalhos e da necessidade de atender às necessidades básicas de todas as crianças, questões que podem ser corrigidas por meio da formação adequada desses educadores. A melhoria da formação e a participação em cursos de capacitações e de formação continuada poderiam reduzir essas dificuldades. A formação de educadores e a redução da razão alunos-professor por turma devem ser implementadas, uma vez que essas situações já são previstas pela legislação, portanto o cumprimento da lei parece ser imprescindível para a melhoria da qualidade da Educação Infantil.

Por fim salienta-se que as ações de saúde e educação devem ser estruturadas tendo como base a implementação de ações de promoção

Movimento, Porto Alegre, v. 15, n. 04, p. 147-173, outubro/dezembro de 2009. 
168 Artigos Orifinais Bárbara Coiro Spessato, et al.

da qualidade de vida das crianças. Cabe salientar que qualquer tentativa de melhorar a qualidade do desenvolvimento infantil, em termos de desenvolvimento motor, tem como contextos primordiais a família e a creche. Portanto, cabe ao educador interagir cada vez mais com a família, propiciando assim um maior comprometimento por parte de todos com relação à saúde e educação da criança.

Movimento, Porto Alegre, v. 15, n. 04, p. 147-173, outubro/dezembro de 2009. 
Children education and motor intervention: a look from the bioecological theory of Bronfenbrenner perspective

Abstract: This study investigated the relations between the enrichment of the daycare context and legislation. Three case studies of babies took place with the theoretical support of the Bioecological theory of human development, designed by Bronfenbrenner. The results showed that the babies developed: many new competencies, manipulative, postural control and social interaction skills. However the quality of care offered by the daycares was restricted to hygiene and feeding. The motor intervention can be implemented in the day care context; however it is necessary to assure that the legislation is held liable when it comes to teacher education and children-teacher ratio to effectively change the assistance character of children education. Keywords: Child Day Care Centers. Legislation as Topic. Early Intervention (Education). Child rearing.

Educación infantil e intervención motriz: una mi-
rada a partir de la teoría bioecológica de
Bronfenbrenner
Resumen: El estudio ha investigado la relación entre
enriquecimiento del contexto de la guardería infantil y la
legislación vigente. Tres estudios de caso con bebés
fueron conducidos en el paradigma de la Teoría Bioeco-
lógica. Los resultados han demostrado que los bebés
presentaron nuevas competencias de manipulación,
control postural e interacción social. Sin embargo, la
calidad de los cuidados que brinda la guardería era
restricta a higiene y alimentación. La intervención puede
ser implementada en el espacio de la guardería; pero es
necesario hacer cumplir la legislación con respecto a la
formación y capacitación de educadores y razón niños-
educadores para efectivamente transformar el carácter
asistencialista de la educación infantil.
Palabras clave: Jardines Infantiles. Legislación como
Asunto. Intervención Precoz (Educación). Crianza del
niño.

\section{REFERÊNCIAS}

ALMEIDA, Carla Skilhan. Intervenção motora: efeitos no comportamento do bebê no terceiro trimestre de vida em creches de Porto Alegre. 2004. 196 f. Dissertação

Movimento, Porto Alegre, v. 15, n. 04, p. 147-173, outubro/dezembro de 2009. 


\section{Artigos Orifinais Bárbara Coiro Spessato, et al.}

(Mestrado em Ciências do Movimento Humano) - Escola de Educação Física, Universidade Federal do Rio Grande do Sul, Porto Alegre, 2004.

ALMEIDA, Carla S.; VALENTINI, Nadia C.; LEMOS, Caroline X. G. A influência de um programa de intervenção motora no desenvolvimento de bebês em creches de baixa renda. Revista Tema Sobre Desenvolvimento, São Paulo, v. 14, n. 83, p.40-48, 2005.

ARNS, Ulrika. Que fazemos com as nossas crianças? um estudo do atendimento das crianças de 0-3 anos nas creches públicas de Cruz Alta. 1998. 142 f. Dissertação (Mestrado em Educação) - Faculdade em Educação nas Ciências, Universidade Regional do Nordeste, Campina Grande, 1998.

BEE, Helen. A criança em desenvolvimento. 7. ed. Porto Alegre: Artes Médicas, 1996.

BERLEZE, A. Desenvolvimento motor de crianças obesas: uma análise de contexto. 2002. 120 f. Dissertação (Mestrado em Ciência do Movimento Humano) Escola de Educação Física, Universidade Federal de Santa Maria, Santa Maria, 2002.

BÉZIER, Marie-Madeline; HUNSINGER, Y. O bebê e a coordenação motora. São Paulo: Summus, 1994

BHERING, Eliana; NEZ, Tatiana B. D. Envolvimento dos pais em creche: possibilidades e dificuldades de parceria. Psicologia teoria e pesquisa, Brasília, v. 18, n. 1, p.6373, 2002.

BOATO, Elvio Marcos. Henri Wallon e a deficiência múltipla: uma proposta de intervenção pedagógica. Brasília: Hildebrando, 2003.

BOMBARDA, Alessandra. Efeitos da intervenção motora em diferentes contextos no desenvolvimento motor da criança com atraso motor. 2008. $124 \mathrm{f}$. Dissertação (Mestrado em Ciências do Movimento Humano) - Escola de Educação Física, Universidade Federal do Rio Grande do Sul, Porto Alegre, 2008.

BRASIL. Constituição, 1988. Constituição da República Federativa do Brasil. Brasília: Senado Federal, 1988.

BRASIL. Lei n ${ }^{\circ} 10.172$, de 9 de janeiro de 2001. Aprova o Plano Nacional de Educação e dá outras providências. Diário Oficial da União, Brasília, DF, 10 jan. 2001. Disponível em: <http://www.planalto.gov.br/ccivil_03/Leis/LEIS_2001/L10172.htm> Acesso em: 21 maio 2008.

BRASIL. Ministério da Educação e do Desporto. Diretrizes Curriculares Nacionais para a formação de Docentes de Educação Infantil e dos anos Iniciais do Ensino Fundamental. Resolução CEB n ${ }^{2}$, de 19 de abril de 1999. Diário Oficial da União, Brasília, 1999. Disponível em: <http://portal.mec.gov.br/cne/arquivos/pdf/rceb02_99.pdf> Acesso em: 21 maio 2008.

. Lei de Diretrizes e Bases $n^{\circ}$ 9.394, de 20 de dezembro de 1996. Diário Oficial da União, Brasília, 1996. Disponível em: <http://www.planalto.gov.br/ccivil_03/ Leis/L9394.htm> Acesso em: 20 maio 2008.

Movimento, Porto Alegre, v. 15, n. 04, p. 147-173, outubro/dezembro de 2009. 
CNE/CEB. Resolução CEB n 1 , de 7 de abril de 1999. Institui as Diretrizes Curriculares Nacionais para a Educação Infantil. Diário Oficial da União, Brasília, 13 abril 1999. Seção 1, p.18. Disponível em: <http://portal.mec.gov.br/cne/arquivos/ pdf/CEB0199.pdf> Acesso em: 20 maio 2008.

BRASIL. Ministério da Educação e do Desporto. Secretaria de Educação Fundamental. Referenciais Curriculares Nacionais para a Educação Infantil. Brasília, 1998. Disponivel em: <http://portal.mec.gov.br/seb/index.php?option=content\&task=view\&id $=556>$ Acesso em: 20 maio 2008 .

Departamento de Políticas Educacionais. Política Nacional de Educação Infantil: pelo direito das crianças de zero a seis anos à educação. Brasília, 2006. Disponível em: <http://portal.mec.gov.br/seb/arquivos/pdf/Educinf/eduinfpolit 2006.pdf> Acesso em: 20 maio 2008.

BRONFENBRENNER, Urie. The Bioecological Model from a Life Course Perspective: reflections of a participant observer. In: MOEN, Phyllis; ELDER, Glen H.; LÚSCHER, Kurt (Eds). Examining lives in context: perspectives on the ecology of human development. Washington, DC: American Psychological Association, 1995. p.599-649.

A ecologia do desenvolvimento humano: experimentos naturais e planejados. 2. ed. Porto Alegre: Artes Médicas, 2002.

Ecological system theory. In: ROSS, Vasta. Six theories of child development: revised formulations and current issues. London: Jessica Kingsley, 1992. p.187-249.

Making human being human: biecological perspectives on human development. Thousand Oaks: SAGE, 2005.

BRONFENBRENNER, Urie; CROUTER, Anne. Evolution of Environmental Models in Developmental Research. In: KESSEN, W.; MUSSEN, Paul H. (Eds.). Handbook of Child Psychology. New York: Wiley, 1983.

BRONFENBRENNER, Urie; MORRIS, Pamela A. The Ecology of developmental process. In: DAMON, I.; LERNER, R. M. (Org.). Handbook of child psychology: theoretical models of human development. New York: John Wiley, 1998. v. 1.

COPETTI, Fernando. Atributos pessoais de crianças que se engajam na prática esportiva: um olhar orientado pelo modelo bioecológico. In: KREBS, Ruy Jornada (Org.) Os processos desenvolvimentais na infância. 1. ed. Belém: GTR, 2003.

EDWARDS, Carolyn; KNOCHE, Lisa; AUKRUST, Vibeke; KUMRU, Asiye; KIM, Misuk. Parental ethnotheories of child development: Loking Beyond Independence and Individualism in American Beliefs System. In: KIM, Uichol; YANG, Kuo- Shu; HWANG, Kwang-kuo (Ed.). Indigenous and cultural psychology understanding people in context. New York: Springer, 2006.

GALLAHUE, David; OZMUN, John C. Compreendendo o desenvolvimento motor: bebês, crianças, adolescentes e adultos. São Paulo: Phorte, 2001.

Movimento, Porto Alegre, v. 15, n. 04, p. 147-173, outubro/dezembro de 2009. 


\section{Artigos Orifinais Bárbara Coiro Spessato, et al.}

HARKNESS, Sara; SUPER, Charles; SUTHERLAND, Mary; BLOM, Marjolijn; MOSCARDINO, Ughetta; MAVRIDIS, Caroline; AXIA, Giovanna. Culture and the construction of habits in daily life: Implications for the successful development of children with disabilities. OTJR: Occupation, participation and health, Bathesda, v. 27, p.33-40, 2007.

HAYWOOD, Katheleen M.; GETCHELL, Nancy. Desenvolvimento motor ao longo da vida. 3. ed. Porto Alegre: Artmed, 2004.

HUIJBREGTS, S; LESEMAN, P.P.M.; TAVECCHIO, L.W.C. Childrearing beliefs of professional caregivers from different cultural communities in the Netherlands. Early Childhood Research Quarterly, Amsterdam, v. 23, p.233-244, 2008.

KREBS, Ruy Jornada. Os processos desenvolvimentais na infância. In: Sociedade Internacional para estudos da criança. Belém: GTR, 2003.

Urie Brofenbrenner e a ecologia do desenvolvimento humano.

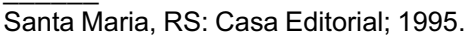

KREBS, Ruy Jornada; ZUCHETTO, Ângela. Os contextos da educação inclusiva numa perspectiva da teoria ecológica de Bronfenbrenner. In: FREITAS, Soraia Napoleão (Org.). Tendências Contemporâneas de Inclusão. 1. ed. Santa Maria: Editora da UFSM, 2008.

LOBO, Michele A.; GALLOWAY, James C.; SALVELSBERGH, Geert J. P. General and task-related experiences affect early object interaction. Child Development, Oxford, v. 75 , n. 4, p.1268-1281, 2004.

LÜSCHER, Kurt. Homo Interpretans: On the Relevance of Perspectives, Knowledge, and Beliefs in the Ecology of Human Development. In: MOEN, Phyllis; ELDER, Glen H.; LÜSCHER, Kurt (Eds.). Examining Lives in Context: perspectives on the ecology of human development. Washington, DC: American Psychological Association, 1995.

MELCHIORI, Ligia E.; ALVES, Zélia M. M.; SOUZA, Dayana C.; BUGLIANI, Maria A. Família e creche: crenças a respeito e temperamento e desempenho de bebês. Psicologia: teoria e pesquisa, Brasília, v. 23 n. 3, p.245-252, 2007.

NEWELL, Karl. Constraints on the development of the coordination. In: WADE M.; WHITING, H.T.A. (Eds.). Motor development in children: aspects of control and coordination. Dordrecht: Martinus Nijhof, 1986.

PAPALIA, Diane E.; OLDS, Sally Wendkos. Desenvolvimento Humano. 7. ed. Porto Alegre: Artes Médicas Sul, 2000.

PINTO, Elizabeth Batista; VILANOVA, Luiz Celso Pereira; VIEIRA, Raymundo Manno. O desenvolvimento do comportamento da criança no primeiro ano de vida: padronização de uma escala para avaliação e comportamento. São Paulo: Casa do Psicólogo,1997.

PIPER, Martha C.; DARRAH, Johanna. Motor assessment of the developing infant. Amsterdan: Elsevier, 1994.

Movimento, Porto Alegre, v. 15, n. 04, p. 147-173, outubro/dezembro de 2009. 
RAMEY, Craig T.; BRYANT, Donna M.; SUAREZ, Tanya M. Early intervention: why, for whom, and at what cost? Clinics in Perinatalogy, Philadelfia, v. 17, n. 1, p.47-55, 1990.

RAMEY, Craig T.; RAMEY, Sharon, L. Prevention of intellectual disabilities: early interventions to improve cognitive development. Preventive Medicine, Nova York, v. 27, n. 2, p.224-232, 1998.

$\mathrm{RECH}$, Daniele M. R. Influências de um programa de intervenção motora com três diferentes abordagens interventivas no desempenho motor de crianças nascidas pré-termo. 2005, 164 f. Dissertação (Mestrado em Ciências do Movimento Humano) - Escola de Educação Física, Universidade Federal do Rio Grande do Sul, Porto Alegre, 2005.

ROCHAT, Phillipe. Dialogical nature of cognition. Monographs of the Society for Research in Child Development, Oxford, v. 66, n. 2, p.133-143, 2001.

ROSE, J. Debra. A multilevel approach to the study of motor control and learning. Needham Heights: Alyn \& Bacon, 1997.

SANTOS, Lana Ermelinda da Silva. Creche e pré-escola: uma abordagem de saúde. São Paulo: Artes Médicas, 2004.

SAVELSBERGH, Geert; HOFSTEN, Claes V.; JONSSON, Bert. The Coupling of Head, Reach and Grasp Movement in Nine Months Old Infant Prehension. Scandinavian Journal of Psychology, Oxford, n. 38, p.325-333, 1997.

SPENCER, John P.; VEREIJKEN, Beatrix; DIEDRICH Frederick J.; THELEN, Esther. Posture and the emergence of manual skills. Developmental Science, Oxford, v. 3, n. 2, p.216-233, 2000.

VIEIRA, José Luiz Lopes. Talento infantil: abordagem sistêmica do processo de abandono de talentos. In: KREBS, Ruy Jornada (Org.). Os processos desenvolvimentais na infância. Belém: GTR, 2003.

WASIK, Barbara H.; RAMEY, Craig T.; BRYANT, Donna M.; SPARLING, J. A longitudinal study of two early interventions strategies: project CARE. Child Development, Oxford, v. 61 , n. 6, p.1682-1696, 1990.

Pesquisa financiada pelo CNPq.

Recebido em: 27.08.2008

Aprovado em: 16.02.2009

Movimento, Porto Alegre, v. 15, n. 04, p. 147-173, outubro/dezembro de 2009. 